\title{
Positive Youth Development Sustainability Scale (PYDSS): The Development of an Assessment Tool
}

\author{
Michael Sieng \\ Arizona State University \\ Scott Cloutier \\ Arizona State University \\ Katherine Irimata \\ Arizona State University
}

Our study details the development of the Positive Youth Development Sustainability Scale, a self-reporting tool to assess the impacts of positive youth development (PYD) programs. The Positive Youth Development Sustainability Scale provides practitioners a tool in the field of PYD both domestically and internationally, addressing the concern of global application and sustainability criteria (e.g., resilience and happiness). First, we conducted a detailed literature review on existing PYD program assessment techniques. Next, we conducted an exploratory factor analysis, via SPSS and AMOS software, to establish the number of factors in the scale. The constructs of the five- $C$ s model (Lerner, 2005; competence, confidence, character, connection, and caring) along with the sixth $C$ (contribution) and happiness were confirmed into six factors. Confirmatory factor analysis was conducted using 2 samples from rural areas of Thailand and the Phoenix, Arizona, metro area $(n=580$ and $n=407$, respectively). Our analysis shows the factor structure was highly comparable with mean comparative fit indices of .930 (Thailand) and .933 (Phoenix metro) for Grades 9-12 and 3-6, respectively. Our study suggests that the tool can be used in different settings and demographics for PYD programs. Future studies should look at the impacts of PYD programs over long periods of time and in a wide range of grades, cultures, and countries to reaffirm multiple applications in various settings.

Keywords: positive youth development, factor analysis, sustainability scale, Southeast Asia, Thailand

\section{Introduction}

Positive youth development (PYD) programs started in the United States and grew out of interest in prevention programs targeting risky behavior of youth (Bumbarger, Perkins, \& Greenberg, 2010; Lerner, 2000; Lorion \& Sokoloff, 2003). PYD programs include intentional efforts by peers, adults, communities, schools, and organizations to provide opportunities for youth to increase their skills, abilities, and interests in positive activities (Catalano, Berglund, Ryan, Lonczak, \& Hawkins, 2004). The goal of PYD is to provide positive outcomes for youth, viewing them as resources to be developed rather than problems to be managed. Current generations rely on youth to be future active and contributing members of society and PYD programs can promote sustainable futures for young individuals. However, while PYD programs have demonstrated success in the United States, based on their own respective program measures, there is a need for an assessment tool for comparative 
analyses across culture, time, and space. Without standards, comparing PYD programs effectively is impossible.

PYD programs are increasingly being expanded internationally, as they promote resilient characteristics and life skills. We suggest that PYD programs are meant to provide long-term opportunities for youth to live meaningful, happy, and sustainable lives. Yet, PYD program assessment tools lack sustainability and happiness measures representative of long-term impacts. In this article, we develop a globally applicable tool to effectively capture sustainability, happiness, and adapted PYD metrics that collaboratively promote future success of youth. Cohn, Fredrickson, Brown, Mikels, and Conway (2009) suggested that happiness, in the form of positive emotions and life-satisfaction, makes one feel better and builds capacity for individuals to develop resources for living well. Happiness actively helps create desirable outcomes and promotes growth in ego resilience, which leads to increased global life satisfaction (Lyubomirsky, King, \& Diener, 2005; Fredrickson, Cohn, Coffey, Pek, \& Finkel, 2008). According to Seligman (2006), there are five elements that drive happiness: (a) positive emotion, (b) engagement, (c) relationships, (d) meaning, and (e) achievement. Nettle (2005) suggested that, to flourish, we need to (a) reduce the impact of negative emotions, (b) increase positive outcomes, and (c) think about other people instead of ourselves. In short, happier people may be more sustainable, and vice versa (Cloutier, Larson, \& Jambeck, 2014).

Since the introduction of sustainable development in 1987 (Brundtland commission) and Agenda 21 as an action plan in 1992 (Sitarz, 1993), there have been many attempts to measure sustainability using various sustainable development indicators (United Nations Department of Economic and Social Affairs, 2001). Researchers have also performed extensive studies on indicators of happiness and well-being and found that happiness is positively correlated with health, material comfort, social equality, and access to knowledge (Veenhoven \& Ehrhardt, 1995). With respect to PYD, moving toward sustainability and happiness first requires youth to have their basic needs met in an environment that reinforces positive behavior. As basic needs are met, long-term happiness can be considered and achieved by focusing on higher level needs (sustainability). There is strong evidence that sustainable development enhances happiness and both have a reinforcing relationship (Cloutier et al., 2014; Zidanšek, 2007). Higher levels of happiness encourage youth to explore the world and to challenge themselves to develop (Park, 2004). Park made an argument that happiness or social wellbeing needs a role in PYD as an indicator, a predictor, a moderator/mediator, and ultimately, as a positive outcome. More, a focus on sustainability and happiness will promote future PYD strategies and research (i.e., longitudinal studies).

The objective of this article is to develop a stronger Positive Youth Development Inventory (PYDI) tool, hereafter referred to as the Positive Youth Development Sustainability Scale (PYDSS), that can be applied in multiple settings or cultures. The PYDSS is adapted from a PYDI assessment tool developed for the 4-H program (Arnold, Nott, \& Meinhold, 2012). Briefly, the 4-H program is the largest PYD and youth mentoring program in the United States, working in partnership with over 110 universities. The 4-H PYDI assessment tool was influenced by Lerner's (2005) five-Cs model (Table 1) as a foundational framework for measuring the assets/characteristics of a PYD program: competence, confidence, character, character, and caring. 
Table 1. The Five Cs as a Foundational Positive Youth Development Framework

\begin{tabular}{lll}
\hline Assets/Characteristic & Definition & Source \\
\hline Competence & Being able to act effectively in & Caplan et al. (1992); Weissberg, \\
& school, in social situations, & Caplan, and Sivo (1989) \\
and at work & Fetterman, Kaftarian, and \\
Confidence & Believing in one's self and & Wandersman (1996) \\
& ability & Kiaget (1952, 1970); Kohlberg \\
Kharacter & and how to do the right thing & $(1963,1969,1981) ;$ Hoffman \\
& & $(1981)$ \\
& Working collaboratively with & Ainsworth, Blehar, Waters, and \\
Connection & parents, peers, siblings, & Wall (1978); Bowlby (1973, \\
& teachers, coaches, or other & 1979, 1982); Mahler, \\
& community members & Bergman, and Pine (1975) \\
Caring & Having a sense of compassion & Salovey and Mayer (1990); \\
& or social justice & Goleman (1995) \\
\hline
\end{tabular}

PYD programs show sustainable impacts in their participants in the form of how much they contribute back to their communities. When youth are demonstrating strengths in all five $C$ s, this leads to a sixth $C$, known as contribution (Lerner, 2004; Lerner, Dowling, \& Anderson, 2003). This means "a young person enacts behaviors indicative of the five $C$ s by contributing positively to self, family, community, and, ultimately, civil society" (Lerner, 2005, p. 8). Lerner et al. (2005) used the five $C$ s to demonstrate an inverse relationship among contribution and negative outcomes or behaviors. Students who had achieved high scores in the five $C$ s were more likely to actively contribute to their local communities showing sustainable impacts of PYD programs. The PYDSS builds on Lerner's (2004) work by including sustainability metrics in happiness and resilience. Our resilience metrics were influenced by Hawkins' social development model (Hawkins \& Catalano, 1996), a model stating that youth who demonstrate active involvement in their family, school, and communities, with positive acknowledgement of their efforts, are more likely to form positive bonds and relationships that suppress risk behaviors showing the importance of support networks (Catalano, Oesterle, Fleming, \& Hawkins, 2004). PYD programs should make youth feel good, but also, and more importantly, elicit life satisfaction in the present and future. Our tool helps to standardize assessment parameters and illustrates a more in-depth approach to PYD programs by providing data on the life satisfaction and well-being of each participant and how support networks influence participants over time.

\section{Methodology}

\section{Positive Youth Development Sustainability Scale (PYDSS) development}

The PYDSS was developed via a detailed search of academic literature in the areas of PYD theory and subjective well-being (happiness). First, we drew on lessons from a cross-disciplinary set of studies of six electronic databases: PubMed, PsycINFO, Web of Science, Science Direct, Scopus, and ERIC. The search was made for all English-language studies with no date limits. Search terms included positive, youth, development, happiness, program, and evaluation and were mapped to database specific subject headings and/or controlled vocabulary terms when available. Common themes and findings from each tool were pulled from the literature search to develop the PYDSS. The literature was then analyzed to cross-reference types of questions or statements that reflect each category of the PYDSS and what could be used based on current tools in practice. Each statement or question had to meet the criteria that it fit into the respective categories of the PYDSS: five $C$ s 
(Eccles \& Gootman, 2002), contribution (Eccles \& Gootman, 2002; Lerner et al., 2005), and happiness (Park, 2004). Questions were included if they overlapped with the PYDI or five- $C$ s framework. The sustainability component was measured by the sixth $C$, contribution, and in questions that can assess the effectiveness of PYD programs over a long period of time. The happiness component was formulated based on subjective well-being scales and other program evaluations that incorporated happiness and have tested for this component. Face validity analysis was conducted by having several PYD experts review the scale for applicability and appropriateness for the target demographic.

\section{PYDSS Pilot Study}

The PYDSS was piloted via a study in the rural areas of Thailand (primarily the Northeast region) and in the Phoenix, Arizona, metro area with a local PYD program for low-income, at-risk youththe Brighter Thailand Foundation and Future for Kids, respectively. The Brighter Thailand Foundation hosts an overnight global leadership camp throughout rural areas of Thailand over 6 days that incorporates a train-the-trainer technique with 15-20 high school students and about 30 primary school students per camp. Future for Kids is an out-of-school-time program focusing on academics, athletics, and ethics activities that takes place during the academic school year once a week for $2 \mathrm{hr}$ for Grades 3-6. These programs were selected based on connections by the author and the prominence of the programs by Peace Corps volunteers in Thailand and program recognition by the Arizona Center for Afterschool Excellence in the Phoenix metro area. The surveys were distributed and administered by Brighter Thailand Foundation and Future for Kids to all student participants before and after the intervention program and each member of the student support network (teachers, parents, and mentors).

The Thai version of the survey was translated into three separate foreign language instructors, trained by the U.S. government to teach Peace Corps volunteers both language and culture. After the three separate translations took place, a consensus was made between the three translators on what was age and culturally appropriate for Thai youth. When the survey was administered, several translators (Thai nationals associated with Peace Corps volunteers) were present who were briefed by the researchers to help answer any questions.

In Thailand, 580 surveys were collected, and in Phoenix, 407 surveys were collected. Each survey captured how the student felt before and after the program using a Likert scale of 1 (strongly disagree), 2 (disagree), 3 (neutral/unsure), 4 (agree), and 5 (strongly agree). Cronbach's alpha was used to determine reliability and internal consistency.

First, exploratory factor analysis (EFA) was used to determine how well the items reflected underlying constructs among the variables in the PYDSS. Principal components analysis and Kaiser's eigenvalue rule were used to identify the number of factors to retain and an oblique rotation solution (promax) was used to identify the simplest structure that would allow for meaningful interpretation (Devellis, 1991). All data analyses were conducted using SPSS Version 23 statistical software.

Second, to evaluate the overall fit of the PYDSS, several fit indices were employed based on the factor solution set obtained from the EFA using confirmatory factor analysis (CFA). These included chi-square, root mean square error of approximation (RMSEA), goodness-of- fit index (GFI), TuckerLewis index (TLI), and comparative fit index (CFI; Schumacker \& Lomax, 2004; Tanaka, 1993). There is a general agreement that values of .9 or greater for GFI, TLI, and CFI indicate a satisfactory fit to the data (Schumacker \& Lomax, 2004). Values of RMSEA below .06 represent an 
acceptable model-data fit (Hu \& Bentler, 1999). Model fit analysis was conducted using AMOS Version 23.

\section{Results}

\section{PYDSS Development Academic Literature Search Results}

The PYDSS was developed via academic literature review and compilation and adapted from Arnold et al. (2012) to include statements derived from a 55-question Likert-scale questionnaire as well as questions derived from various happiness scales. The results of the PYDSS literature search are provided in Table 2.

Table 2. Positive Youth Development Sustainability Scale Literature Search

\begin{tabular}{|c|c|}
\hline Item & Source \\
\hline \multicolumn{2}{|l|}{ Happiness } \\
\hline $\begin{array}{l}\text { Happiness can be measured in the moment, overall, or as life satisfaction with } \\
\text { measurement tools such as The Subjective Happiness Scale, the Positive and } \\
\text { Negative Affect Schedule, and the Satisfaction with Life Scale. }\end{array}$ & $\begin{array}{l}\text { Lyubomirsky and Lepper } \\
\text { (1999); Watson, Clark, and } \\
\text { Tellegen (1988); Diener, } \\
\text { Emmons, Larsen, and Griffin } \\
\text { (1985) }\end{array}$ \\
\hline $\begin{array}{l}\text { Life satisfaction/happiness should play a role in PYD as an indicator, as (a) life } \\
\text { satisfaction is correlated with physical health and healthy behaviors; (b) } \\
\text { negative life satisfaction is linked to violent problem behaviors; (c) negative } \\
\text { life satisfaction is correlated with depression, anxiety, neuroticism, and } \\
\text { loneliness, and (d) youth life satisfaction is positively correlated with } \\
\text { desirable psychological characteristics. }\end{array}$ & $\begin{array}{l}\text { Park (2004); Valois, Zullig, } \\
\text { Huebner, and Drane (2001); } \\
\text { Huebner (1991); McKnight, } \\
\text { Huebner, and Suldo (2002) }\end{array}$ \\
\hline $\begin{array}{l}\text { The ultimate goal of youth development programs should be achieving good } \\
\text { quality of life for participants rather than just preventing or mitigating } \\
\text { psychopathology. }\end{array}$ & $\begin{array}{l}\text { Park (2004); Coie et al. (1993); } \\
\text { Cowen (1994); Durlak and } \\
\text { Wells (1997) }\end{array}$ \\
\hline \multicolumn{2}{|l|}{ Resilience } \\
\hline $\begin{array}{l}\text { Resilience took root in the creation of positive development as a conceptual } \\
\text { model. }\end{array}$ & $\begin{array}{l}\text { Benson, Scales, Hamilton, and } \\
\text { Sesma (2006); Masten (2001) }\end{array}$ \\
\hline $\begin{array}{l}\text { Researchers began to realize that resilience was not a trait inherent in } \\
\text { children, but a function of their ecology. This ecological approach formed into } \\
\text { three broad sets of protective factors embedded in resilience: those (a) within } \\
\text { a child, (b) within the family, and (c) within the broader social ecology. }\end{array}$ & $\begin{array}{l}\text { Luthar, Cicchetti, and Becker } \\
\text { (2000); Masten and Garmezy } \\
\text { (1985) }\end{array}$ \\
\hline $\begin{array}{l}\text { The primary means of incorporating positive development is via intervention } \\
\text { and prevention programs. One prime example of this approach is Hawkins' } \\
\text { social development model, which stated that youth who experience positive } \\
\text { developmental opportunities showcasing active involvement in their family, } \\
\text { school, and communities, with acknowledgement of their efforts, are more } \\
\text { likely to form positive bonds and relationships that suppress risk behaviors. }\end{array}$ & $\begin{array}{l}\text { Benson et al. (2004); Catalano, } \\
\text { Berglund, et al. (2004) }\end{array}$ \\
\hline
\end{tabular}

\section{Five Cs Plus Contribution}

The PYDI is a collection of items designed to measure changes in levels of PYD programs. The version produced by Arnold et al. (2012) follows the five- $C$ s model of youth development, by measuring the constructs of confidence, competence, character, caring, and connection. This version also includes the measurement of a sixth $C$, contribution. The PYDSS expands from the PYDI from a 4-point scale: 1 (strongly disagree), 2 (disagree), 3 (agree), and 4 (strongly agree) to a 5-point scale including a neutral/unsure score. With the addition of happiness construct, the total number of questions was reduced to 32 questions instead of 55. To include a resilience component, members of the students' support groups also measured the students adding depth of more than one perspective. 


\section{Factor Analysis and Statistical Results}

\section{Factor Analysis}

A scree plot (Cattell, 1966) verified the number of factors to be rotated using the promax method with Kaiser normalization. The resulting factor structure indicated that a six-factor solution provided the optimal number of interpretable factors without unduly reducing the percentage of total variance accounted for in the Thai dataset. In the Phoenix dataset, EFA indicated that a three-factor solution was optimal. To be included, an item was required to load at the .40 level or higher on one factor. Three items in the Thai dataset and four items in the Phoenix dataset did not meet this criterion and were removed. The remaining 29 items (Thai) and 28 items (Phoenix) and their factor loadings are presented in Table 3.

Table 3. Percentage of Total Variance, Mean, and Standard Deviation of Factors for the Positive Youth Development Sustainability Scale Datasets

\begin{tabular}{lccc}
\hline Item & $\begin{array}{c}\text { \% Total } \\
\text { Variance }\end{array}$ & $\boldsymbol{M}$ & $\boldsymbol{S D}$ \\
\hline Thailand & & & \\
Factor 1. Happiness/Confidence & 42.174 & 4.22 & .870 \\
Factor 2. Caring & 5.718 & 4.00 & .860 \\
Factor 3. Connection & 5.123 & 4.12 & .870 \\
Factor 4. Contribution & 4.442 & 3.90 & .860 \\
Factor 5. Competence & 3.780 & 4.20 & .850 \\
$\quad$ Factor 6. Character & 3.580 & 4.04 & .820 \\
Phoenix & & & \\
$\quad$ Factor 1. Caring/Character/ & 44.714 & 3.98 & 1.08 \\
$\quad$ Competence & & & \\
$\quad$ Factor 2. Happiness/ Connection & 5.401 & 4.13 & 1.01 \\
$\quad$ Factor 3. Contribution/Confidence & 4.314 & 3.85 & 1.15 \\
\hline
\end{tabular}

The factors were labeled by identifying the construct that most of the questions related to. Tables 4 and 5 contain the percentage of total variance, mean, and standard deviations for each factor. The $p$ values for the Kaiser-Meyer-Olkin measure of sampling adequacy and Bartlett's test of sphericity were not statistically significant at the $5 \%$ significance level for both datasets.

\section{Reliability}

The PYDSS had Cronbach's alpha reliability statistics of .951 (Thai) and .952 (Phoenix), which is greater than the reliability minimum of .7 (George \& Mallery, 2003). George and Mallery (p. 231) provided the following as guidelines: >.9, excellent; >.8, good; >.7, acceptable; >.6, questionable; >.5, poor; and $<.5$, unacceptable. Table 6 includes the Cronbach's alpha reliability statistics for each factor.

\section{Model Fit}

Model fit was calculated using the six-factor solution from the Thai dataset from the EFA and confirmed fit using CFA for both datasets analyzed. Questions were removed based on low factor loadings or redundancy. Tables 7 and 8 and Figures 1 and 2 display the final output for the PYDSS. 
Table 4. Factor Loadings of Items From the Positive Youth Development Sustainability Scale Thai Dataset

\begin{tabular}{lc}
\hline Item & Factor Loading \\
\hline Factor 1: Happiness/confidence & .905 \\
I am happy at home. & .691 \\
I am happy at school. & .426 \\
I am happy in this program. & .426 \\
I am happy with the people in my life. & .606 \\
I am satisfied with my life. & .808 \\
I feel connected to my parents. & .431 \\
I feel like I am worth something. & .551 \\
Factor 2: Caring & .671 \\
When others need help, I help them. & .780 \\
It is easy for me to know how others feel. & .764 \\
I try to encourage others when they are not as good at something as me. & .697 \\
I can be counted on to help if someone needs me. & .863 \\
I care about the feelings of my friends. & .775 \\
Factor 3: Connection & .834 \\
I have many different types of friends. & .533 \\
My friends care about me. & .650 \\
I feel connected to my friends. & .552 \\
I feel connected to my teachers. & \\
I have people in my life I look up to and admire. & .830 \\
I have close friendships. & .651 \\
Factor 4: Contribution & .718 \\
I take an active role in my community. & .697 \\
I am someone who gives to benefit others. & .642 \\
I like to work with others to solve problems. & .862 \\
I have things I can offer to others. & .835 \\
It is important for me to try and make a difference in the world. & .427 \\
Factor 5: Competence & .765 \\
I have goals in my life. & .429 \\
I know what I want to be when I grow up. & .537 \\
Factor 6: Character & \\
I like to learn new things. & I can manage my emotions. \\
It is important for me to do the right thing. & \\
If I promise to do something I can be counted on to do it. & \\
\hline
\end{tabular}

Note. Statistical significance determined by factor loading >.4. 
Table 5. Factor Loadings of Items From the Positive Youth Development Sustainability Scale Phoenix Dataset

\begin{tabular}{lc}
\hline Item & Factor Loading \\
\hline Factor 1: Caring/character/competence & .877 \\
It is important for me to do the right thing. & .737 \\
I like to learn new things. & .648 \\
If I promise to do something, I can be counted on to do it. & .642 \\
I have goals in my life. & .596 \\
I can be counted on to help if someone needs me. & .596 \\
I can manage my emotions. & .523 \\
I try to encourage others when they are not as good at something as me. \\
I know what I want to be when I grow up. & .500 \\
I have people in my life I look up to and admire. & .490 \\
When others need help, I help them. & .479 \\
I care about the feelings of my friends. & .411 \\
Factor 2: Happiness/connection & .826 \\
I am happy at home. & .761 \\
I am satisfied with my life. & .714 \\
I am happy with the people in my life. & .713 \\
I feel connected to my family. & .694 \\
I have close friendships. & .644 \\
My friends care about me. & .622 \\
I have many different types of friends. & .477 \\
I am happy in this program. & .435 \\
I feel connected to my parents. & .888 \\
Factor 3: Contribution/confidence & .727 \\
I have things I can offer to others. & .700 \\
I am someone who gives to benefit others. & .651 \\
I take an active role in my community. & .618 \\
I like to work with others to solve problems. & .554 \\
It is important for me to try and make a difference in the world. \\
It is easy for me to know how others feel. \\
I feel like I am worth something. \\
I am happy at school. & .491 \\
\hline
\end{tabular}

Note. Statistical significance determined by factor loading >.4.

Table 6. Cronbach's Alpha Reliability Statistics for Positive Youth Development Sustainability Scale Factors Datasets

\begin{tabular}{ll}
\hline Item & $\alpha$ \\
\hline Thailand & \\
Factor 1: Happiness/confidence & .870 \\
Factor 2: Caring & .870 \\
Factor 3: Connection & .856 \\
Factor 4: Contribution & .859 \\
Factor 5: Competence & .813 \\
Factor 6: Character & .752 \\
Phoenix & .893 \\
Factor 1: Caring/character/competence & .896 \\
Factor 2: Happiness/connection & .879 \\
Factor 3: Contribution/confidence &
\end{tabular}

Note. Statistical significance determined by $\alpha>.7$. 
Table 7. Confirmatory Factor Analysis Model Fit Summary

\begin{tabular}{lccc}
\hline & Statistical & \multicolumn{2}{c}{ Fit Statistics } \\
\cline { 3 - 4 } Statistic & Significance & Thai Dataset & Phoenix Dataset \\
\hline$\chi^{2}(d f)$ & & $852.233(284)$ & $662.954(284)$ \\
CMIN/df & Range $2-3$ & 3.001 & 2.334 \\
RMSEA & $<.06$ & .059 & .057 \\
GFI & $>.90$ & .896 & .888 \\
TLI & $>.90$ & .920 & .924 \\
CFI & $>.90$ & .930 & .933 \\
\hline
\end{tabular}

Note. CMIN = minimum chi square; RMSEA = root mean square error of approximation; GFI =goodness-of-fit index; TLI = Tucker-Lewis index; CFI = comparative fit index.

Table 8. Standardized Factor Loadings of Items From the Positive Youth Development Sustainability Scale Confirmatory Factor Analysis Model Output

\begin{tabular}{|c|c|c|}
\hline \multirow[b]{2}{*}{ Item } & \multicolumn{2}{|c|}{ Factor Loading } \\
\hline & Thailand & Phoenix \\
\hline \multicolumn{3}{|l|}{ Factor 1: Happiness/confidence } \\
\hline I am happy at home. & .74 & .73 \\
\hline I am happy at school. & .79 & .67 \\
\hline I am happy in this program. & .73 & .68 \\
\hline I am happy with the people in my life. & .76 & .80 \\
\hline I am satisfied with my life. & .73 & .73 \\
\hline I feel like I am worth something. & .63 & .60 \\
\hline \multicolumn{3}{|l|}{ Factor 2: Caring } \\
\hline When others need help, I help them. & .76 & .75 \\
\hline It is easy for me to know how others feel. & .72 & .70 \\
\hline I try to encourage others when they are not as good at something as me. & .82 & .80 \\
\hline I can be counted on to help if someone needs me. & .76 & .83 \\
\hline I care about the feelings of my friends. & .72 & .71 \\
\hline \multicolumn{3}{|l|}{ Factor 3: Connection } \\
\hline I have people in my life I look up to and admire. & .63 & .66 \\
\hline I have many different types of friends. & .73 & .66 \\
\hline My friends care about me. & .81 & .66 \\
\hline I feel connected to my friends. & .79 & .73 \\
\hline I feel connected to my teachers. & .66 & .72 \\
\hline \multicolumn{3}{|l|}{ Factor 4: Contribution } \\
\hline I take an active role in my community. & .67 & .72 \\
\hline I am someone who gives to benefit others. & .70 & .80 \\
\hline I like to work with others to solve problems. & .71 & .71 \\
\hline I have things I can offer to others. & .81 & .66 \\
\hline It is important for me to try and make a difference in the world. & .76 & .80 \\
\hline \multicolumn{3}{|l|}{ Factor 5: Competence } \\
\hline I have goals in my life. & .82 & .74 \\
\hline I know what I want to be when I grow up. & .83 & .60 \\
\hline \multicolumn{3}{|l|}{ Factor 6: Character } \\
\hline I like to learn new things. & .63 & .71 \\
\hline It is important for me to do the right thing. & .72 & .73 \\
\hline If I promise to do something I can be counted on to do it. & .66 & .71 \\
\hline
\end{tabular}



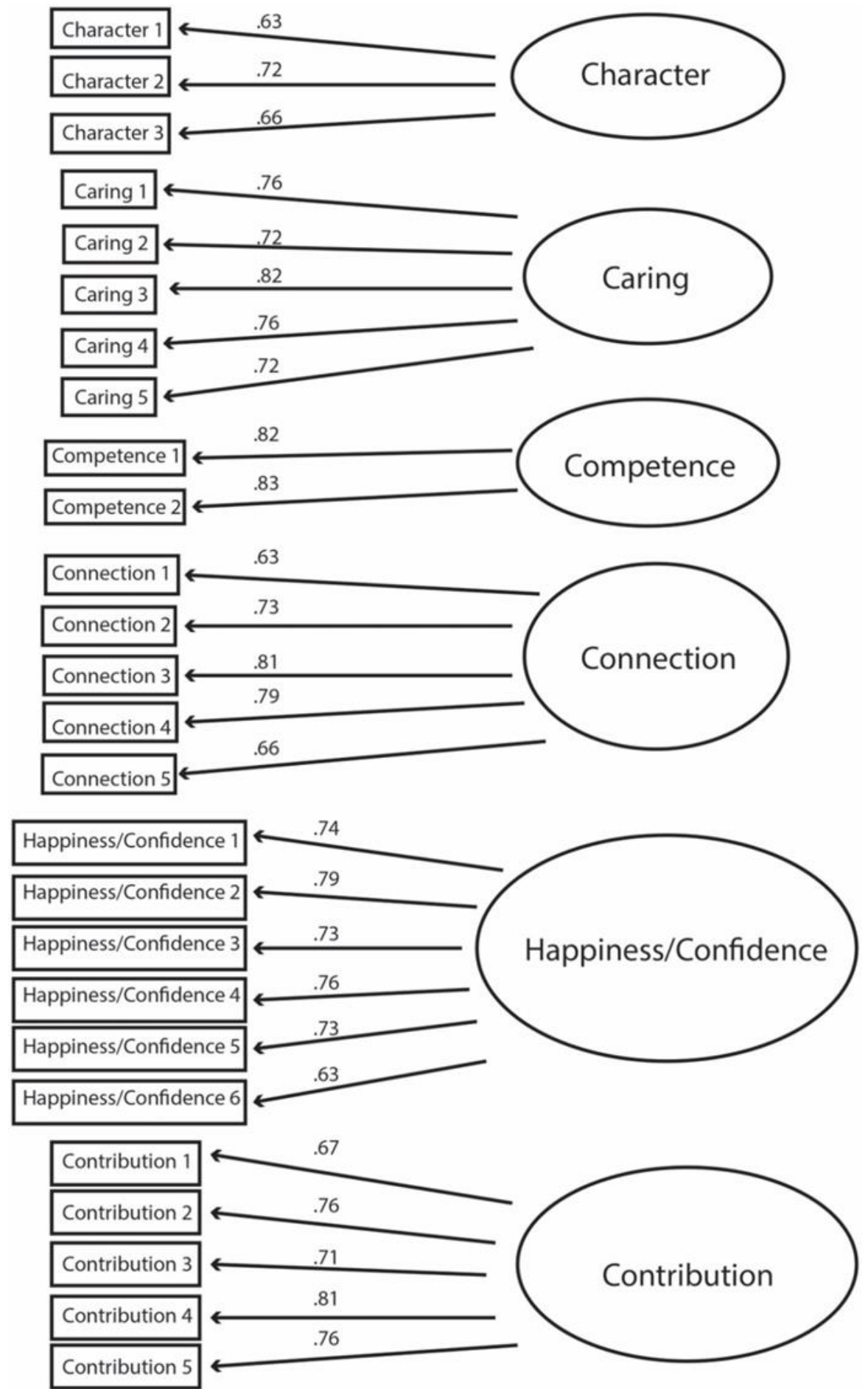

Figure 1. Comparative Factor Analysis-Thai Dataset. The boxes represent questions pertinent to the circled factor, and the number shows the loading. 

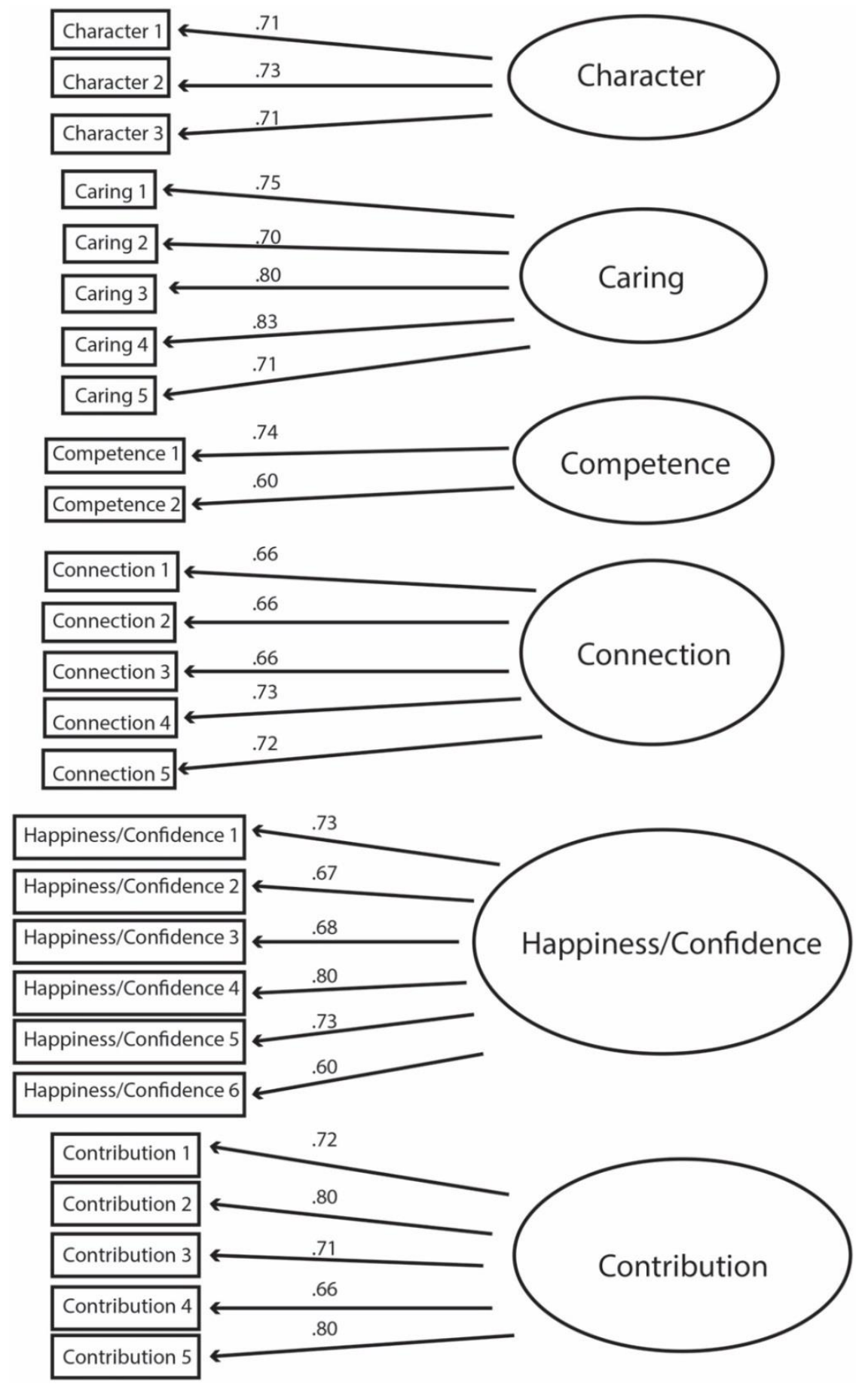

Figure 2. Comparative Factor Analysis-Phoenix Dataset. The boxes represent questions pertinent to the circled factor, and the number shows the loading. 


\section{Discussion}

The purpose of developing the PYDSS is to create a tool that can be used in multiple settings to measure PYD programs in multiple countries and cultures. As PYD programs continue to grow, there is a pressing need to develop globally applicable relevant measures of PYD (Dukakis, London, McLaughlin, \& Williamson 2009). Creating a tool for assessing PYD programs provides guidance for future empirical research and for the evaluation of youth-serving programs seeking to promote PYD domestically and internationally. Next, we will provide a summary of the methodology, results, implications, limitations, and opportunities for future research.

Several recent reviews of the literature have presented evidence of empirical support for the validity and robustness of the five- $C$ s model of PYD (Heck \& Subramaniam, 2009). In its current form, however, the PYDI only measures the five $C$ s (plus contribution) - there is a need to expand the scope to include sustainability measures like happiness. To address this concern, EFA and CFA of PYD programs were conducted with the Brighter Thailand Foundation (Grades 9-12) and Phoenix's Future for Kids (Grades 3-6). These programs have similarities in the foundation of creating an environment for PYD, but also have strong differences in their techniques and demographics of the students. The PYDSS was created by adapting measures from the PYDI, also adding happiness as a component and surveying support networks of students in Phoenix and Thailand. Model fit tests were also conducted using both data sets to assess potential for multiple applications for different types of PYD programming in different cultural settings. The initial results indicate that several questions needed to be removed to ensure greater model fit for both data sets and supports the notion of global application.

The items that were removed in the CFA model were "I can manage my emotions" and "I have close friendships," due to low factor loadings and repetition in the given category, respectively. With the removal of these items, the PYDSS is now within statistical significance of the majority of the model fit tests we used in our CFA with both datasets, showing the ability to be used in multiple settings across different programs and demographics.

The EFA of the Thailand data indicate that six categories (constructs) were determined, closely resembling the PYDI and PYD literature, while the Phoenix data show only three categories. However, both datasets fit the six-factor model developed from the EFA results for the Thai dataset. The CFA confirmed the proposed six-factor solution with acceptable model fit, which suggests that the five $C$ s with contribution and happiness have a significant role in predicting PYD. Given high Cronbach's alpha values for both datasets (Thai dataset $\alpha=.951$, Phoenix dataset $\alpha=.952$ ), it is possible that more questions might be removed in future versions of the PYDSS to reduce the time required to complete the survey, while not compromising the quality of the results. Removal of additional items could also result in better fit for the CFA model of the PYDSS.

Finally, as youth age, the importance of their relationships becomes more significant overtime. Thus, surveying all support network members including mentors, teachers, and parents provided insight on how in tune each individual is with respect to students. Even though the survey was administered to all support members of each youth participant, response rates varied and were limited in some cases. Future studies focusing on student support networks could lead to new discoveries through full participation of the study. In the conversations with support networks, we also captured their responses through interviews and in some cases this showed a willingness to participate. This could lead to future studies that focus on qualitative or a mixed methods approach in data collection. 
The present research addresses limitations present in both the empirical and applied realms of PYD. Although the PYD framework has become more popular among practitioners and academics, there is some disagreement on indicators of positive development that spans across research, policy, and practice on a global scale (Moore, Lippman, \& Brown, 2004). Earlier work (Lerner et al., 2005; Phelps et al., 2009) already established the existence of a valid measure of PYD across early adolescence in developed countries like the United States. The present work extends the validity and utility of the measure to adolescents in developing countries. Researchers examining application in a rural or urban setting globally now have a valid measure to assess whether youth are developing positively. This work also affords researchers the ability to consider the relationships among PYD and sustainability measures like happiness and how they relate to one another.

Our methods have their own limitations that require future investigation. First, although our results suggest that the initial five- $C$ s model-plus contribution and happiness-shows fit for two distinct groups locally and globally, the conclusion was drawn based on results obtained with a sample that is different from the Phelps et al. (2009) and the Arnold et al. (2012) samples. There is a possibility that the original measurement structure does not fit all youth in all countries due to the fact every culture and every PYD program is different. One challenge with this and any evaluation tool is the time this takes away from actual programming. This survey on average took between 20 and $40 \mathrm{~min}$ to complete, while the ideal time would be between 10 and $15 \mathrm{~min}$. Another challenge encountered in the process was translation and cultural adaptation. If expanding to other cultures in different languages, sensitivity around this area should be considered. In some cases, the PYDSS might be more effective administered orally or as a guide for interviews and focus groups for cultures and communities that are strongly influenced by oral traditions. We also captured responses to the PYDSS questions via focus groups and interviews in Thailand, and in many cases, participants were more open to sharing personal experience in the PYD program with specific examples of how they changed. The PYDSS also leaves room for modification for other program specific questions or additional questions to each criterion. In the future, this tool can be used as a baseline assessment of a PYD program, ensuring that all areas align with PYD theory and literature. Future studies should use the PYDSS in a wide range of grade levels, culture, and countries to reaffirm multiple applications.

While our research is limited by our sample, measurement model, and methodology, the support we have provided for the present conceptualization of PYD enhances our understanding of application in diverse settings domestically and internationally, as well as how PYD might be studied longitudinally and the PYDSS may be used in application. Therefore, future research should track youth and their support networks over long periods of time and in different countries and cultures to see how the program has impacted them. Essentially, longitudinal studies can capture sustainability of the programs impact on youth participants and their happiness after the PYD programs. The overall goal of PYD programs should be to promote happiness and life satisfaction, and PYD tools like the PYDSS can track this over time.

\section{References}

Ainsworth, M. D. S., Blehar, M. C., Waters, E., \& Wall, S. (1978). Patterns of attachment. Hillsdale, NJ: Lawrence Erlbaum Associates.

Arnold, M. E., Nott, B. D., \& Meinhold, J. L. (2012). The positive youth development inventory. Corvallis, OR: Oregon State University 4-H Youth Development Program.

Benson, P. L., Scales, P. C., Hamilton, S. F., \& Semsa, A., Jr. (2006). Positive youth development: Theory, research, and applications. In W. Damon \& R. M. Lerner (Ed.), Handbook of child 
psychology, Vol. 1: Theoretical models of human development (6th ed., pp. 894-941). Hoboken, NJ: Wiley.

Bowlby, J. (1973). Attachment and loss: Vol. 2: Separation-anxiety and anger. New York, NY: Basic Books.

Bowlby, J. (1979). On knowing what you are not supposed to know and feeling what you are not supposed to feel. The Canadian Journal of Psychiatry, 24, 403-408.

Bowlby, J. (1982). Attachment and loss: Retrospect and prospect. American Journal of Orthopsychiatry, 52, 664-678.

Bumbarger, B., Perkins, D. F., \& Greenberg, M. (2010). Taking effective prevention to scale. In B. Doll, W. Pfohl, \& J. Yoon (Eds.), Handbook of youth prevention science (pp. 433-444). New York, NY: Routledge.

Caplan, M., Weissberg, R. P., Grober, J. S., Sivo, P. J., Grady, K., \& Jacoby, C. (1992). Social competence promotion with inner-city and suburban young adolescents: Effects on social adjustment and alcohol use. Journal of Consulting and Clinical Psychology, 60, 56-63.

Catalano, R. F., Berglund, M. L., Ryan, J. A., Lonczak, H. S., \& Hawkins, J. D. (2004). Positive youth development in the United States: Research findings on evaluations of positive youth development programs. The Annals of the American Academy of Political and Social Science, $591,98-124$.

Catalano, R. F., \& Hawkins, J. D. (1996). The social development model: A theory of antisocial behavior. In J. D. Hawkins (Ed.), Cambridge criminology series: Delinquency and crime: Current theories (pp. 149-197). New York, NY: Cambridge University Press.

Catalano, R. F., Oesterle, S., Fleming, C. B., \& Hawkins, J. D. (2004). The importance of bonding to school for healthy development: Findings from the Social Development Research Group. Journal of School Health, 74, 252-261.

Cattell, R. B. (1966). The scree test for the number of factors. Multivariate Behavioral Research, 1, $245-276$.

Cloutier, S., Larson, L., \& Jambeck, J. (2014). Are sustainable cities "happy" cities? Associations between sustainable development and human well-being in urban areas of the United States. Environment, Development and Sustainability, 16, 633-647.

Cohn, M. A., Fredrickson, B. L., Brown, S. L., Mikels, J. A., \& Conway, A. M. (2009). Happiness unpacked: Positive emotions increase life satisfaction by building resilience. Emotion, 9, 361368.

Coie, J. D., Watt, N. F., West, S. G., Hawkins, J. D., Asarnow, J. R., Markman, H. J., \& Long, B. (1993). The science of prevention: A conceptual framework and some directions for a national research program. American Psychologist, 48, 1013-1022.

Cowen, E. L. (1994). The enhancement of psychological wellness: Challenges and opportunities. American Journal of Community Psychology, 22, 149-179.

Devellis, R. F. (1991). Applied social research methods series, Volume 26: Scale development: Theory and application. Newbury Park, CA: Sage.

Diener, E. D., Emmons, R. A., Larsen, R. J., \& Griffin, S. (1985). The Satisfaction With Life Scale. Journal of Personality Assessment, 49, 71-75. 
Dukakis, K., London, R. A., McLaughlin, M., \& Williamson, D. (2009). Positive youth development: Individual, setting and system level indicators (Issue brief: Positive youth development indicators). Stanford, CA: John W. Gardner Center for Youth and Their Communities.

Durlak, J. A., \& Wells, A. M. (1997). Primary prevention mental health programs for children and adolescents: A meta-analytic review. American Journal of Community Psychology, 25, 115152.

Eccles, J., \& Gootman, J. A. (Eds.). (2002). Community programs to promote youth development. Washington, DC: National Academy Press.

Fetterman, D. M., Kaftarian, S. J., \& Wandersman, A. (1996). Empowerment evaluation: Knowledge and tools for self-assessment and accountability. Thousand Oaks, CA: Sage.

Fredrickson, B. L., Cohn, M. A., Coffey, K. A., Pek, J., \& Finkel, S. M. (2008). Open hearts build lives: Positive emotions, induced through loving-kindness meditation, build consequential personal resources. Journal of Personality and Social Psychology, 95, 1045-1062.

George, D., \& Mallery, P. (2003). SPSS for Windows step by step: A simple guide and reference (11.0 update; 4th ed.). Boston, MA: Allyn \& Bacon

Goleman, D. P. (1995). Emotional intelligence: Why it can matter more than IQ for character, health and lifelong achievement. London, United Kingdom: Bloomsbury.

Hawkins, J. D., \& Catalano, R. F. (1996). Parents who care: A step by-step guide for families with teens. San Francisco, CA: Jossey-Bass/Pfeiffer.

Heck, K. E., \& Subramaniam, A. (2009). Youth development frameworks [Monograph]. Davis, CA: 4H Center for Youth Development, University of California.

Hoffman, L. (1981). Foundations of family therapy: A conceptual framework for systems change. New York, NY: Basic Books.

Hu, L. T., \& Bentler, P. M. (1999). Cutoff criteria for fit indexes in covariance structure analysis: Conventional criteria versus new alternatives. Structural Equation Modeling: A Multidisciplinary Journal, 6, 1-55.

Huebner, E. S. (1991). Initial development of the Student's Life Satisfaction Scale. School Psychology International, 12, 231-240.

Kohlberg, L. (1963). The development of children's orientations toward a moral order. Human Development, $6,11-33$.

Kohlberg, L. (1969). Stage and sequence: The cognitive-developmental approach to socialization. In D. A. Goslin (Ed.), Handbook of socialization theory and research (pp. 347-480). Chicago, IL: Rand McNally.

Kohlberg, L. (1981). The philosophy of moral development moral stages and the idea of justice. Cambridge, United Kingdom: Harper \& Row.

Lerner, R. M. (2000). Developing civil society through the promotion of positive youth development. Journal of Developmental and Behavioral Pediatrics, 21, 48-49.

Lerner, R. M. (2004). Liberty: Thriving and civic engagement among America's youth. Thousand Oaks, CA: Sage.

Lerner, R. M. (2005). Promoting positive youth development: Theoretical and empirical bases. Paper presented at the Workshop on the Science of Adolescent Health and Development, National Research Council/Institute of Medicine, Washington, DC. 
Lerner, R. M., Dowling, E. M., \& Anderson, P. M. (2003). Positive youth development: Thriving as the basis of personhood and civil society. Applied Developmental Science, 7, 172-180.

Lerner, R. M., Lerner, J. V., Almerigi, J. B., Theokas, C., Phelps, E., Gestsdottir, S., ... Smith, L. M. (2005). Positive youth development, participation in community youth development programs, and community contributions of fifth-grade adolescents: Findings from the first wave of the 4-H study of positive youth development. The Journal of Early Adolescence, 25, $17-71$.

Lorion, R. P., \& Sokoloff, H. (2003). Building assets in real-world communities. In R. M. Lerner \& P. L. Benson, (Eds.), Developmental assets and asset-building communities (pp. 121-156). New York, NY: Springer.

Luthar, S. S., Cicchetti, D., \& Becker, B. (2000). The construct of resilience: A critical evaluation and guidelines for future work. Child Development, 71, 543-562.

Lyubomirsky, S., King, L., \& Diener, E. (2005). The benefits of frequent positive affect: Does happiness lead to success? Psychological Bulletin, 131, 803-855.

Lyubomirsky, S., \& Lepper, H. S. (1999). A measure of subjective happiness: Preliminary reliability and construct validation. Social Indicators Research, 46, 137-155.

Mahler, M., Bergman, A., \& Pine, F. (1975). The psychological birth of the infant: Symbiosis and individuation. New York, NY: Basic.

Masten, A. S. (2001). Ordinary magic: Resilience processes in development. American Psychologist, $56,227-237$.

Masten, A. S., \& Garmezy, N. (1985). Risk, vulnerability, and protective factors in developmental psychopathology. In B. Lahey \& A. Kazdin (Eds), Advances in clinical child psychology (pp. 1-52). New York, NY: Springer.

McKnight, C. G., Huebner, E. S., \& Suldo, S. (2002). Relationships among stressful life events, temperament, problem behavior, and global life satisfaction in adolescents. Psychology in the Schools, 39, 677-687.

Moore, K. A., Lippman, L., \& Brown, B. (2004). Indicators of child well-being: The promise for positive youth development. Annals of the American Academy of Political and Social Science, $591,125-145$.

Nettle, D. (2005). An evolutionary approach to the extraversion continuum. Evolution and Human Behavior, 26, 363-373.

Park, N. (2004). The role of subjective well-being in positive youth development. The Annals of the American Academy of Political and Social Science, 591, 25-39.

Phelps, E., Zimmerman, S., Warren, A. A., Jelicic, H., von Eye, A., \& Lerner, R. M. (2009). The structure and developmental course of positive youth development (PYD) in early adolescence: Implications for theory and practice. Journal of Applied Developmental Psychology, 30, 571-584.

Piaget, J. (1952). The origins of intelligence in children (M. Cook, Trans.). New York, NY: W W Norton \& Co. doi:10.1037/11494-000

Piaget, J. (1970). The stages of the intellectual development of the child. In P. Mussen, J. Conger, \& J. Kagan (Eds.), Readings in child development and personality (pp. 291-302). New York, NY: Harper \& Row.s 
Schumacker, R. E., \& Lomax, R. G. (2004). A beginner's guide to structural equation modeling. Mahwah, NJ: Erlbaum.

Seligman, M. E. (2006). Learned optimism: How to change your mind and your life. New York, NY: Vintage.

Sitarz, D. (1993). Agenda 21: The Earth summit strategy to save our planet. Boulder, CO: EarthPress.

Tanaka, J. S. (1993). Multifaceted conceptions of fit in structural equation models. Sage Focus Editions, 154, 10-39.

United Nations Department of Economic and Social Affairs. (2001). Energy for sustainable development of the least developed countries in Africa. New York, NY: Author.

Valois, R. F., Zullig, K. J., Huebner, E. S., \& Drane, J. W. (2001). Relationship between life satisfaction and violent behaviors among adolescents. American Journal of Health Behavior, $25,353-366$.

Veenhoven, R., \& Ehrhardt, J. (1995). The cross-national pattern of happiness: Test of predictions implied in three theories of happiness. Social Indicators Research, 34, 33-68.

Watson, D., Clark, L. A., \& Tellegen, A. (1988). Development and validation of brief measures of positive and negative affect: the PANAS scales. Journal of Personality and Social Psychology, 54, 1063-1070.

Weissberg, R., Caplan, M., \& Sivo, P. (1989). A new conceptual framework for establishing schoolbased social competence promotion programs. In L. A. Bond \& B. E. Compas (Eds.), Primary prevention and promotion in the schools (pp. 255-296). Thousand Oaks, CA: Sage.

Zidanšek, A. (2007). Sustainable development and happiness in nations. Energy, 32, 891-897.

The Journal of Social Change, sponsored by Walden University, welcomes manuscripts focusing on interdisciplinary research in social change that improves the human condition and moves people, groups, organizations, cultures, and society toward a more positive future.

Walden University Publishing: http://www.publishing.waldenu.edu 